\title{
TRADIÇÃO NA ÉPICA GREGA ARCAICA
}

\author{
Adrian Kelly \\ Balliol College, University of Oxford
}

Resumo. O que foi legado a Homero é fonte de um desacordo sempre crescente entre os estudiosos modernos, não apenas referente ao "o que" de sua herança mas até mesmo ao "como". Dicotomias mais antigas estabeleceram uma forte distinção entre os elementos recorrentes na poesia Homérica e os toques individuais, rotulando o primeiro de "tradição" e o segundo de "inovação". Estudos mais recentes, entretanto, têm mostrado a inter-relação essencial e constante desses dois conceitos: há uma individualidade constante na formação e no desenvolvimento mesmo das características mais comuns, ao passo que os elementos aparentemente mais inovadores da poesia homérica mostram a influência da padronização e tipicidade que viemos a esperar. Em outras palavras, a tradição é sempre inovadora, e a inovação é sempre tradicional. Ainda assim, essa reciprocidade parece ter sido ignorada em dois ramos importantes da pesquisa homérica moderna, os quais podemos chamar de Neoanálise e de Orientalismo: ambas essas escolas de pensamento compartilham pressuposições sobre o contexto textual e tradicional de Homero que são insustentáveis. Esse artigo remeterá a alguns exemplos famosos dessas duas abordagens, e sugere um contra-argumento "tradicional" a ambos. Palavras-chave. Oralismo, Homero, Neoanálise, Orientalismo, Antigo Oriente Próximo, lamento prospectivo.

\footnotetext{
“TradiçÃo" É UM dos termos MAIS FUndAMENTAIS, EMbORA CADA VeZ mais controverso, no estudo da épica grega arcaica. De fato, a noção de tradição em si e sua relação com a oralidade, é atualmente o campo de batalha de algumas das polêmicas mais ardentes nos estudos homéricos. Parte da explicação para essa situação é histórica: depois de Milman Parry, os estudiosos das Clássicas tiveram que se acertar com o fato de que velhas certezas sobre a tradição homérica precisavam ser reconfiguradas em relação à Ilíada e à Odisseia, sem mencionar a escassez de remanescentes do restante da épica grega arcaica. Ou seja, em vez de ser capaz de assumir várias formas de precursores escritos, textuais, do tipo familiar a períodos posteriores da Antiguidade, tornou-se claro que um processo fragmentado e variado, amplamente, senão somente, de natureza oral estava para ser o alvo da investigação. Se alguém quisesse apreciar Homero, tinha de lidar com sua tradição oral.
} 
Isso era - e permanece sendo - uma noção perturbadora, pois tal fenômeno é necessariamente incerto, efêmero, difícil de definir ou de ser posto em uma árvore genealógica. Que era uma noção perturbadora pode ser visto claramente em algumas das primeiras reações às ideias de Parry, e ao fato de que, no início, elas se espalharam lentamente e quase exclusivamente dentro de círculos anglófonos. Que permanece um conceito perturbador até mesmo hoje pode ser deduzido, por exemplo, da obra mais recente de Martin West, que é a destilação do estudo de uma vida inteira sobre a poesia épica homérica e grega arcaica. ${ }^{1}$ Ali, West trata " $\mathrm{P}$ " - seu nome para o poeta da Ilíada - como uma figura letrada, que interage tanto com predecessores gregos quanto do Oriente Próximo de modo similar a, digamos, como Virgílio o faz com Homero. Para West, "P" está no final de uma tradição oral e a transcende. Assim, a influência do contexto oral sobre Homero foi quase totalmente eliminada do cômputo, e retornamos a onde estávamos antes de Parry. A tradição é agora, mais uma vez, reconfortantemente escrita.

Martin West não está sozinho, embora ele talvez seja bem radical; uma gama inteira de obras nos últimos trinta anos tem procurado de modo consistente marginalizar a importância da tradição oral para leitores e críticos da Ilíada e da Odisseia. ${ }^{2}$ Pode-se listar e depois responder cada um dos argumentos desses autores, mas quero isolar aqui as duas razões principais para o que parece ser um distanciamento geral, em alguns lugares, das descobertas e princípios do "oralismo". Isso aconteceu por causa da combinação recente de duas áreas de estudo originalmente separadas. ${ }^{3}$

A primeira é a crescente influência da Neoanálise, aquela escola de estudos homéricos que acredita poder reconstruir as fontes de Homero ao comparar seus poemas com o chamado Ciclo Épico, que eram poemas aparentemente mais antigos, dos quais a Ilíada e a Odisseia beberam. ${ }^{4}$ Por um longo período, de modo geral, confinada ao mundo germanófono, ela começou a ganhar ritmo na Grã-Bretanha muito em função dos esforços de Malcolm Willcock, nas décadas de 1980 e 1990, mas tem se difundido em

West 2011.

2 Cf. Kelly 2011, 4-5, para alguns exemplos, e passim para uma tentativa de mostrar como uma apreciação da tradição nos permite abordar questões interpretativas em uma base mais sólida.

${ }^{3}$ Claro, a atual situação deve-se também ao fato de que a escola oralista não tem sido capaz de persuadir alguns públicos não simpatizantes, e assim tem se tornado cada vez mais propensa a dirigir seus argumentos àqueles que já foram persuadidos de sua razão. Conforme um colega comentou comigo há vários anos, às vezes tudo isso parece um pouco procul, procul este profani!

${ }^{4}$ Paraumaintrodução ehistória, cf. Willcock 1997e, agora, Montanari, Rengakos \& Tsagalis 2012. 
uma aclamação quase universal, mesmo entre oralistas..$^{5}$ A segunda área é a influência similarmente nascente (agora quase uma adolescente) do que pode ser chamado "Orientalismo", a revelação do antecendente cultural do Antigo Oriente Próximo para a cultura grega arcaica, um processo cujas raízes podem ser traçadas bem ao longe na história dos estudos clássicos, e cujos campeões modernos são Walter Burkert e (mais uma vez) Martin West. A obra original de Burkert foi publicada em 1984, mas foi somente por meio de uma tradução publicada em 1992 que ela se tornou amplamente conhecida no mundo anglófono, ao passo que o monumental East Face of Helicon de West mudou a face dos estudos sobre Grécia arcaica para sempre. ${ }^{6}$

Juntas, essas duas abordagens modelaram o curso recente dos estudos homéricos mais do que qualquer outra, e não apenas porque os proponentes de uma são naturalmente simpatizantes da outra. ${ }^{7}$ Há uma afinidade natural entre esses dois métodos de análise, porque são ambos conduzidos por um desejo equivocado (do meu ponto de vista) de procurar pelas "fontes" de Homero, no sentido mais estreito do termo. ${ }^{8}$ A tradição oral épica grega não pode ser confinada a poemas individuais ou a linhas ou movimentos individuais de influência entre esses poemas, como se culturas (e poetas, no que diz respeito ao assunto) se comportassem como tradições impessoais de manuscritos, agindo e sendo conduzidos de modos mais ou menos previsíves - e geralmente passíveis de serem descobertos.

Infelizmente, entretanto, esses modelos um tanto lineares têm se tornado populares mais uma vez, ao ponto de uma cura externa ser agora quase o tratamento padrão para qualquer mal-estar homérico: ${ }^{9}$ a Neoanálise nos direciona a poemas épicos gregos arcaicos fixos a serem submetidos à nossa posologia, e o orientalismo somente amplia esse processo para a literatura suméria, babilônica, hitita, assíria, hebraica. Juntos, esses dois ramos das pesquisas nos oferecem um Homero que não é meramente Virgílio setecentos anos antes, mas um Virgílio incrivelmente douto, multilíngue e multicultural. Um über-Virgílio, por assim dizer.

${ }^{5}$ Cf. a crescente influência da Neoanálise na obra de Jonathan Burgess, nos escritos de 1996, 1997-2001 e, atualmente, 2009.

${ }^{6}$ Cf. West 1971 para os primeiros sinais (embora eles já pudessem ser encontrados em 1966, em seu comentário à Teogonia), 1997; Burkert 1984, 1992 etc.

${ }^{7}$ Para uma abordagem neoanalítica, cf., por exemplo, West 2003, e compare os tratamentos mutuamente excludentes da Diapeira (sobre os quais cf., abaixo, pp. 13-6) em West 1997, 207-8, e West 2011, 100-8, o primeiro de uma perspectiva orientalista e o segundo de uma perspectiva analista. Para uma abordagem neoanalítica e neoanalítico-orientalista, cf. Currie 2006 e 2012, respectivamente.

${ }^{8}$ Cf. Kelly 2008, 260-2.

9 A metáfora foi deliberadamente escolhida, refletindo o fato de que muito das pesquisas em questão se baseia em identificar e explicar as "falhas" ou "problemas" na poesia homérica. 
Desse modo, não é a noção de que havia uma tradição pré-homérica que é contestada, pois ambos, neoanalistas e orientalistas, acreditam que Homero é o produto de uma tradição. Em vez disso, estamos brigando sobre o conteúdo e influência dessa tradição. Seria, como os oralistas têm tentado nos mostrar nos últimos oitenta e tantos anos, um fenômeno variado e flexível marcado por uma dinâmica principalmente oral? Ou seria, como neoanalistas e orientalistas defendem, um fenômeno fixo e amplamente previsível, com um texto alimentando outro de modo costumeiro, e com o poeta homérico como a figura transcendente que condena a épica anterior ao esquecimento?

Embora descrições mais nuançadas dessas escolas e seus métodos sejam possíveis, ${ }^{10}$ essa concepção combinada culmina em um processo no qual uma panaceia externa e externalizadora nos conduz para longe dos textos. Ou seja, somos encorajados a nos distanciar do que sabemos - que Homero herdou uma longa tradição oral - para especular sobre o que não sabemos - que Homero pode ou não ter conhecido e usado deliberadamente versões fixas, escritas de narrativas gregas e não gregas. Essa última posição não pode ser descartada, claro; simplesmente não sabemos se não havia uma massa de textos, gregos ou do Antigo Oriente Próximo, com os quais Homero estava interagindo. Mas é certamente mais seguro começar com o que sabemos, e é a proposta desse artigo demonstrar os benefícios de proceder assim.

\section{CASO 1: AS LÁGRIMAS DE TÉTIS}

Meu primeiro caso é famoso - a enxurrada de lamentações dirigidas ao mortal Aquiles por sua mãe no início do Livro 18 da Ilíada, mais particularmente a ação de segurar-lhe a cabeça. ${ }^{11}$ Desde Johannes Kakridis, quase todo mundo reconhece que essa ação - devidamente confinada a circunstâncias de lamento, em que o principal lamentador segura a cabeça do cadáver - tem algo a ver com o processo de um funeral. ${ }^{12}$ Visto que Aquiles não está morto, tal ação pode ser considerada um tanto incomum, e ela de

${ }_{10}$ Como exemplos, cf. Most 1997 e Haubold 2002, 2006, bem como o no prelo.

${ }^{11}$ Essa é uma versão menor de Kelly 2012, o qual sugiro ao leitor para um argumento mais completo e nuançado (embora os erros devam ter permanecido os mesmos).

${ }_{12}$ Cf. Kakridis 1949, 65-75. 
fato tem encontrado seus críticos..$^{13}$ A morte de Aquiles de tal modo foi claramente parte da tradição épica homérica, pois Homero faz Agamêmnon lembrar Aquiles dela no famoso, e famosamente controverso, final da Odisseia (24.35-94). ${ }^{14}$ Portanto, deve haver uma alusão àquela história nas ações de Tétis no início do Livro 18, e seria possível acrescentar à ação de segurar a cabeça uma série inteira de ações que são encontradas mais comumente em contextos de lamento: a presença e choro das Nereidas, a posição de Aquiles na areia etc. ${ }^{15}$

Uma geração mais antiga de neoanalistas considerou essas características problemáticas e sugeriu que esse era um caso em que Homero não tinha escondido ou recriado adequadamente suas fontes. Uma geração mais recente reverteu essa linha argumentativa, sugerindo não que Homero tenha falhado, mas que ele estivesse usando esses episódios levemente fora de lugar a fim de assinalar sua relação ou interação alusiva com aquelas fontes. Essa geração mais recente é também levemente mais realista ao não ser tão devotada à noção de textos fixos, embora tanto as conclusões quanto os processos de sua metodologia permaneçam praticamente os mesmos. ${ }^{16}$ Mas o que é importante para meu propósito é o nível de significância que eles atribuem a essa função externa, essa alusão à história / canção / poema / texto da morte de Aquiles. Ou seja, o modo como eles leem Homero depende inteiramente do fato da alusão. Eu facilmente admito ser provável algum tipo de referência à morte de Aquiles nessa cena. Afinal, no último terço da Ilíada, o poeta é amiúde explícito sobre suas menções ao futuro, e não apenas sobre Aquiles. ${ }^{17}$

Mas seria esse o propósito dessa cena, ou mais especificamente de seus elementos que foram certa vez taxados de "inadequados" e são agora considerados "alusivos"? Em outras palavras, seria essa a única, ou mesmo a mais importante, função desses elementos no contexto da Ilíada? Sugiro que não. Meu ponto de partida é a tradição oral homérica, ou o que podemos reconstruir dela. Todos nos acostumamos às sequências típicas, mas uma que parece ter escapado ao olhar geral é o "lamento prospectivo", o uso de cenas características de lamento / pranto em que elas são menos adequadas,

${ }_{13}$ Cf. Pestalozzi 1945, 26-7, 32; Kullmann 1960, 36-7, 331-2; Schoeck 1961, 43-4; Schadewaldt 1965, 166; Danek 1998, 470-1; Edwards 1991, 311-12; contra Fenik 1964, 31-3; Foley 1991, 157-9; Dihle 1970, 20-2; Kelly 2012.

${ }^{14}$ Cf., mais recentemente, Kelly 2007a, com bibliografia.

${ }_{15}$ Todas essas características, entretanto, precisam ser interpretadas dentro do quadro típico do lamento prospectivo.

${ }_{16}$ Compare a obra de Edwards 1991 ou Currie 2006 com as de Pestalozzi 1945 e de Schoeck 1961.

${ }_{17}$ Cf., especialmente, Burgess 2009. 
isto é, em que a figura que é objeto do lamento não está de fato morta. ${ }^{18}$ Na verdade, um exame de todas essas cenas da Ilíada e da Odisseia revela tanto a frequência de seu emprego quanto o fato de que há uma sequência a esse emprego; há uma estrutura básica bipartite, na qual um lamento em público encontra reprovação e é então seguido de um lamento privado (às vezes com outra reprovação), como disposto abaixo: $:^{19}$

\section{A. Primeira ocasião (pública)}

\begin{tabular}{|c|c|c|c|}
\hline & Local & Lamentação & Reprovação \\
\hline (1) & $\begin{array}{l}\text { Campo de batalha } \\
\left.\text { (Il. } 4 \cdot 79^{-80}\right)\end{array}$ & $\begin{array}{l}\text { Agamêmnon } \\
(148-9)\end{array}$ & $\begin{array}{l}\text { Menelau } \\
(183-7)\end{array}$ \\
\hline (2) & $\begin{array}{l}\text { Portas Ceias } \\
(\text { Il. 6.392-4) }\end{array}$ & $\begin{array}{l}\text { Andrômaca } \\
(406-39)\end{array}$ & $\begin{array}{l}\text { Heitor } \\
(441-65)\end{array}$ \\
\hline (3) & $\begin{array}{l}\text { Gruta de Neleu } \\
\left(I l .18 .35^{-6}\right)\end{array}$ & $\begin{array}{l}\text { Tétis } \\
(18.51-64)\end{array}$ & - \\
\hline (4) & $\begin{array}{l}\text { Casa de Príamo } \\
(\text { Il. } 24 \cdot 160-1)\end{array}$ & $\begin{array}{l}\text { resumo } \\
(160-)\end{array}$ & $\begin{array}{l}\text { Íris } \\
(171-87)\end{array}$ \\
\hline (5) & $\begin{array}{l}\text { Área pública da casa de Od. } \\
(\text { Od. 1.330-5) }\end{array}$ & $\begin{array}{l}\text { Penélope } \\
(336-44)\end{array}$ & $\begin{array}{l}\text { Telêmaco } \\
(345-59)\end{array}$ \\
\hline (6) & $\begin{array}{l}\text { Soleira das alas femininas } \\
(\text { Od. } 4 \cdot 679-80)\end{array}$ & $\begin{array}{l}\text { Penélope } \\
(680-95,703-10)\end{array}$ & $\begin{array}{l}\text { Médon } \\
(711-14)\end{array}$ \\
\hline (7) & $\begin{array}{l}\text { Área pública da casa de Od. } \\
(\text { Od. 19.51-2) }\end{array}$ & $\begin{array}{l}\text { Penélope (resumo) } \\
(204-13,249-51)\end{array}$ & $\begin{array}{l}\text { Odisseu } \\
(582-7)\end{array}$ \\
\hline (8) & (a) despensa da casa de Od. & $\begin{array}{l}\text { Penélope (resumo) } \\
(55-6)\end{array}$ & - \\
\hline & $\begin{array}{l}\text { (b) área pública da casa de Od. } \\
\text { (Od.21.63-6) }\end{array}$ & $\begin{array}{l}\text { Penélope } \\
\text { (67-79 etc.) }\end{array}$ & $\begin{array}{l}\text { Telêmaco } \\
(344-53)\end{array}$ \\
\hline
\end{tabular}

${ }^{18}$ Há oito casos identificáveis dessa sequência, listados abaixo em termos de referência ao sujeito/objeto do luto: (1) Agamêmnon - Menelau (Il. 4.148-82), (2) Andrômaca - Heitor (Il. 6.319-502), (3) Tétis - Aquiles (Il. 18.35-145), (4) Hécuba - Príamo (Il. 24.191-328), (5) Penélope - Odisseu (Od. 1.328-64), (6) Penélope - Telêmaco (Od. 4.679-758), (7) Penélope - Odisseu (Od. 19.53-604), (8) Penélope - Odisseu (Od. 21.55-358).

${ }^{19}$ Duas dessas sequências, (3) e (4), revertem a progressão geral público > privado. O primeiro exemplo é nosso caso atual, e o reverso é causado aqui porque o poeta deseja fazer Tétis viajar do campo grego até a casa de Hefesto depois que o prospecto de luto estiver concluído. Alhures, uma vez que a mulher foi colocada em ambiente privado, o foco narrativo a deixa lá e se move para outro lugar. A mesma motivação explica a outra reversão (4), pois Príamo tem de ir até a tenda de Aquiles e voltar; cf. Kelly 2012, 241-2, 247-9. 


\section{B. Segunda ocasião (pública)}

\begin{tabular}{|c|c|c|c|}
\hline & Local & Lamentação & Reprovação \\
\hline (1) & - & - & - \\
\hline (2) & $\begin{array}{l}\text { Casa de Heitor } \\
(\text { Il. } 6.497-8)\end{array}$ & $\begin{array}{l}\text { Andrômaca e criadas } \\
\text { (resumo) }(498-502)\end{array}$ & - \\
\hline (3) & $\begin{array}{l}\text { Naus dos Mirmidões } \\
(\text { Il. 18.67-9) }\end{array}$ & $\begin{array}{l}\text { Tétis } \\
(70-7,95-5)\end{array}$ & $\begin{array}{l}\text { Aquiles } \\
(97-126)\end{array}$ \\
\hline (4) & $\begin{array}{l}\text { Quarto de Príamo } \\
(\text { Il. 24.191-2, 237-8, 281-2) }\end{array}$ & $\begin{array}{l}\text { (a) Hécuba }(200-16) \\
\text { (b) troianos }(237) \\
\text { (c) filhos }(249-51)\end{array}$ & $\begin{array}{l}\text { Príamo }(217-27) \\
\text { Príamo }(239-46) \\
\text { Príamo }(252-64)\end{array}$ \\
\hline (5) & $\begin{array}{l}\text { Alas femininas } \\
(O d \cdot 1.360-2)\end{array}$ & $\begin{array}{l}\text { Penélope e criadas } \\
\text { (res.) }(362-3)\end{array}$ & - \\
\hline (6) & $\begin{array}{l}\text { (Soleira das) alas femininas } \\
(\text { Od. } 4.716-19)\end{array}$ & $\begin{array}{l}\text { Penélope } \\
(721-41)\end{array}$ & $\begin{array}{l}\text { Euricleia } \\
(742-58)\end{array}$ \\
\hline (7) & $\begin{array}{l}\text { Alas femininas } \\
(\mathrm{Od} .19 .600-2)\end{array}$ & $\begin{array}{l}\text { Penélope e criadas } \\
\text { (res.) }(602-3)\end{array}$ & - \\
\hline (8) & $\begin{array}{l}\text { Alas femininas } \\
(O d .21 .354-6)\end{array}$ & $\begin{array}{l}\text { Penélope e criadas } \\
\text { (res.) }(356-7)\end{array}$ & - \\
\hline
\end{tabular}

A importância dessa percepção está no fato de que ambos, poeta e público, estavam cientes de que a ação era típica, e assim eles podem não ter achado incongruente a presença daqueles elementos no início do Livro 18 como tem parecido a muitos estudiosos modernos. Isso não impede que aqueles elementos tenham um propósito alusivo, claro, mas reduz consideravelmente a necessidade de enxergá-los desse modo; afinal, o caso neoanalista foi fundado originalmente na noção de que eles poderiam apenas fazer sentido na Ilíada quando vistos como derivados de, ou alusivos a, outra história / canção / poema / texto. Assim, temos de descobrir, se possível, que função a cena parece ter em outros contextos homéricos, a fim de entender o que o poeta poderia estar tentando fazer nesse caso.

Uma coisa que parece universal a esses lamentos prospectivos é o fato de que a figura lamentada está em algum tipo de grande perigo, contexto no qual não é desarrazoado para a figura que lamenta expressar preocupações sobre a provável falta de segurança daquele que é lamentado: por exemplo, a preocupação de Agamêmnon com seu irmão é fundada em seu 
ferimento um tanto visível (Il. 4.155-82), e ampliada pelo fato de que Menelau é importante para a expedição como um todo; a preocupação de Penélope com Telêmaco não é apenas conduzida pelo fato de que ele a deixou sozinha em casa, mas também por ele ter ido vagar por um mundo onde vagar é uma atividade violenta e perigosa, mesmo que não se considerasse os desígnios dos pretendentes ( $\mathrm{Od}$. 4.663-72); ao passo que Andrômaca reconhece os perigos do menos de Heitor, que o faz sempre combater à frente, e certamente não está equivocada em pensar que essa possa ser a última vez que ela o verá. De fato, quando ela volta para casa, ela e suas servas lamentam Heitor explicitamente nesses termos (Il. 6.501-2)!

É pouco menos aparente a razão pela qual Tétis deveria estar preocupada com Aquiles no Livro 18 da Ilíada. Ela está num estado semiconstante de sofrimento, e Jonathan Burgess argumenta bem que ela é tradicionalmente vista como um personagem que tenta constantemente adiar a morte do filho. ${ }^{20}$ Talvez haja alguma referência a essa capacidade de autoflagelação por causa da extensão de seu sofrimento, como Antíloco assume quando este dá a Aquiles a notícia (Il. 18.32-4). Mas a resposta, considerando a natureza da preocupação de Tétis, é na verdade mais ligada à segunda característica universal dessas cenas de lamento prospectivo - que o lamentador está na verdade equivocado em relação a seu receio imediato.

Agamêmnon, por exemplo, está equivocado em temer por Menelau, pois ele não está destinado a morrer em Troia, e o poeta se estende para explicar ao público externo que o ferimento não é e não pode ser mortal. Penélope está equivocada em temer por Telêmaco, porque ele está na verdade - se podemos confiar na Telegonia - destinado a viver sua existência imortalmente com Circe; ele certamente não corre perigo na Odisseia, pois Atena o está protegendo. Penélope está também equivocada em temer pela segurança de Odisseu em suas várias cenas desse tipo, pois Odisseu ou está a caminho de casa ou em algum lugar da própria casa. Mesmo Andrômaca está equivocada em lamentar Heitor no Livro 6, pois ele voltará para casa uma última vez, com o exército no final do Livro 7. Alguém pode facilmente argumentar que, claro, a verdadeira fonte do receio de Andrômaca é a morte violenta de seu marido no campo de batalha, que é o que acontece no Livro 22. Isso é verdade, e eu não desejo negar a habilidade do poeta em conduzir seu público para um luto real dentro da própria Ilíada. Entretanto, ao menos parte do maravilhamento dessa última sequência, e o modo como ela é dividida entre os Livros 22 e 24, é que é um tanto incomum que um lamento prospectivo esteja ligado a um luto real. Muitos críticos notaram

${ }^{20}$ Cf., especialmente, Burgess 2009. 
como a Ilíada parece terminar em uma cadência lúgubre com o funeral de Heitor, e uma compreensão das práticas usuais da épica ajuda a salientar quão única é essa cena final. ${ }^{21}$

Mas, para nossos propósitos, o importante parece ser o equívoco do lamentador sobre o perigo imediato que está diante da figura amada. Esses lamentos prospectivos, em outras palavras, têm uma função maior e reiterada dentro de seus próprios contextos narrativos - assinalar a natureza equivocada ou prematura da totalmente razoável preocupação expressa pela figura que lamenta. Como isso funciona no Livro 18 da Ilíada? Uma das crucis mais intratáveis no poema é a previsão de Tétis em 18.95-6 sobre o momento da morte de seu filho. ${ }^{22}$ Estudiosos têm, compreensivelmente, se preocupado com essa passagem: alguns argumentam que Homero não sabia das Amazonas, ou de Mêmnon; outros que ele estava tentando ocultá-los, removê-los da história para que criasse uma narrativa com mais autoridade, que focasse na importância de Heitor para a história de Troia, e sua morte como seu momento mais importante. Mas uma função do lamento prospectivo, parece, é assinalar o equívoco - e assim a previsão de Tétis está simplesmente equivocada. Como Andrômaca, como Agamêmnon, como Penélope, Tétis está simplesmente errada sobre o momento da morte de seu filho. Homero não impossibilita que outras histórias se interponham entre seu poema e a morte de seu personagem principal, e não há mais qualquer dificuldade interpretativa sobre os versos 95-96 do Livro 18 da Ilíada.

${ }^{21}$ Embora eu não deseje assumir que precisamos privilegiar apenas o primeiro (ou alguns primeiros) público de Homero, aquele grupo para o qual essa narrativa da ira de Aquiles era novidade, também não devemos negligenciá-lo. Exatamente como Telêmaco assevera a popularidade da "mais nova canção", temos de lembrar que o poeta não precisa ter imaginado um público que estava tão intimamente familiarizado com a totalidade do texto da Ilíada ou da Odisseia como estamos. Por conseguinte, devemos estar alertas à possibilidade da novidade e da incerteza na narrativa como uma parte integral da intenção do poeta, como narrativa em desenvolvimento da morte de Heitor. Que ele vai morrer na Ilíada é sinalizado pela primeira vez no final do Livro 8 por Zeus (473-7, esp.

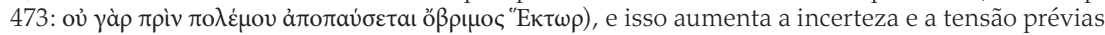
derivadas do lamento prospectivo de Adrômaca. Nesse caso, o público é então encorajado a indagar sobre como o encontro inevitável e fatal com Aquiles será engendrado nessa narrativa, porque eles "sabem" que não vai acontecer nessa fase atual do combate. Cf. também o modo no qual a vitória de Heitor no terceiro dia de combate é garantida dentro de um quadro temporal limitado (11.191-4 206-9). O público está cada vez mais na expectativa do encontro de Heitor com seu fim nas mãos de Aquiles (um fato pré-estabelecido), mas essa expectativa é remodelada no curso da Ilíada, e Homero continua adiando o momento determinante.

${ }^{22}$ Curri 2006, 31, tenta evitar o problema, enquanto mergulha de cabeça: "the poet need not always have his eye on how a putative continuation of his song could be reconciled with tradition ... Iliad 18.96 'quotes' the *Memnonis (Aithiopis) while simultaneously negating its plot" (contra, e.g., Scodel 2004, passim); West 2003, 7, considera que é um "cochilo" homérico, e Kullmann 1960, 37-9, explica a previsão de Tétis se referindo aos típicos erros dos poetas orais (cf. contra Lohmann 1970, 142); Burgess 2009, 87: "the remark by Thetis is a transferred motif that evokes the situation before the battle between Achilles and Memnon" (contra Hölscher 1955, 394-5). 
Este caso, então, ilustra o êxito interpretativo ao apreciar a interação de Homero com sua tradição. Não como os neoanalistas têm defendido, em termos de seu uso defeituoso, problemático ou mesmo alusivo de uma história / canção / poema / texto prévio, mas no emprego de seus padrões típicos, tradicionais, herdados. As lágrimas de Tétis no início do Livro 18 da Ilíada fazem sentido, antes de tudo, no contexto daquele poema.

Este caso também nos mostra as possibilidades de uma combinação das perspectivas neoanalítica e oralista: embora eu não negue uma função alusiva a essa cena, nego que tal função seja a dominante ou a parte mais importante do que está acontecendo no início do Livro 18 da Ilíada. Ainda que uma alusão mais ou menos como as de períodos posteriorres não possa ser excluída, ela não parece ser particularmente importante aqui. Na melhor das hipóteses, ela tem uma função subordinada. Em suma, quando focamos nossa atenção no que o poeta de fato sabia e usava, então podemos ver com muito mais clareza o que ele realmente estava fazendo na Ilíada. Externalizar nesse caso, e em muitos outros, é arriscar errar o alvo.

\section{CASO 2: O TESTE DE EXÉRCITOS}

Se devemos ser cuidadosos ao nos voltarmos automaticamente para outra história / canção / poema / texto quando se trata de abordarmos problemas homéricos, então a transposição de barreiras linguísticas e culturais devem se apresentar com um alerta ainda maior. Meu segundo exemplo concerne ao caso da relação entre Homero e o Antigo Oriente Próximo, e especificamente a porção da Bíblia hebraica, do Deuteronômio ao segundo livro dos Reis, que é geralmente denominada a "História Deuteronômica". ${ }^{23}$ Desde muito, Homero parece propício a ser comparado com narrativas heroicas da Bíblia, e uma gama de estudiosos tem documentado suas várias semelhanças. ${ }^{24}$ Muito desse trabalho é feito por razões puramente analógicas, mas alguns argumentos recentes sugerem que o texto hebraico ou sua tradição influenciou Homero diretamente. Mais uma vez, esses estudiosos

\footnotetext{
${ }^{23}$ Esta é uma versão bastante condensada da primeira parte de Kelly 2003, à qual o leitor pode se dirigir para uma versão mais completa, mas não menos errônea, do argumento. A segunda parte desse texto, não resumida aqui, procura mostrar quão isolada e incomum é a poesia homérica quando comparada com os textos do Antigo Oriente Próximo, no que concerne o deleite detalhado e estruturado que ela alcança com a narrativa de batalha.

${ }^{24}$ Cf., por exemplo, Gordon 1967; de Vaux 1972; Niditch 1993, 104-5; Knox \& Russo 1989; West 1997, passim; Hamblin 2006.; contra, por exemplo, Frolov \& Wright 2011, que rompem a ligação homérica em favor de tradições mais antigas do Antigo Oriente Próximo, e Taylor 2007, 24-7.
} 
têm sido compelidos por um problema interpretativo da Ilíada a olhar para fora de Homero, dessa vez até para fora da área da língua grega, para encontrar uma solução.

O problema é a Diapeira no Livro 2 da Ilíada, em que Agamêmnon decide testar a disposição de seu exército em combater, fingindo querer deixar Troia. Estudiosos têm se questionado diante de vários elementos dessa cena, incluindo a sabedoria de sugerir a fuga a um exército há muito longe de casa, a natureza desmotivadora do teste em si e o modo como é introduzido. ${ }^{25}$ Alguns críticos, em resposta, relacionam o episódio à incompetência de Agamêmnon como líder, ansiando por transformar em virtude os vícios narrativos que seus oponentes detectaram, mas neste artigo quero focar naqueles estudiosos que têm procurado a solução em outro lugar, ${ }^{26}$ nesse caso no Livro dos Juízes, especificamente a passagem na qual o herói Gideão testa seus apoiadores (7.2):

(2) O SENHOR disse a Gideão, "As tropas contigo são muitas para que eu coloque os madianitas nas mãos delas. Israel ficaria simplesmente com o meu crédito, dizendo que 'Minhas próprias mãos me libertaram'. (3) Agora então proclame isto para que as tropas ouçam, 'Quem quer que tema e trema, que volte para casa'." Assim Gideão passou-as por um pente-fino; vinte e dois mil retornaram, e dez mil permaneceram. ${ }^{27}$

Outro teste reduz de forma ainda mais drástica os números, e a vitória é conquistada em seguida. Esse "teste" pode ser ligado com Deuteronômio 20.8:

Os oficiais devem continuar a se dirigir às tropas, dizendo: "Há alguém temeroso ou desmotivado? Ele deve voltar para sua casa, ou pode fazer com que o coração de seus companheiros também amoleçam como o dele próprio". ${ }^{28}$

À luz dessas duas passagens, Roland Knox e Joseph Russo propuseram um costume subjacente - um "teste de desencorajamento" -, embora as passagens sejam um tanto diferentes: em Juízes o teste é planejado para diminuir as forças de Gideão e tornar manifesto o papel de Deus na vitória, no Deuteronômio o teste soa como uma reflexão militar. Eles não parecem particulamente relacionados ou mesmo consistentes o suficiente para sugerir um costume subjacente. Além disso, o motivo é isolado nos textos das

${ }^{25}$ Cf. Latacz et al. 2003, 29-30, 40-1, com Sehnert-Siebel 1994, Cook 2003.

${ }^{26}$ Cf., especialmente, Knox \& Russo 1989, West 1997.

27 "(2) The LORD said to Gideon, 'The troops with you are too many for me to give the Midianites into their hand. Israel would only take the credit away from me, saying 'My own hand has delivered me.' (3) Now therefore proclaim this in the hearing of the troops, 'Whoever is fearful and trembling, let him return home." Thus Gideon sifted them out; twenty-two thousand returned, and ten thousand remained" (ed. New Oxford Standard Revised Version).

${ }_{28}$ "The officials shall continue to address the troops, saying 'Is anyone afraid or disheartened? He should go back to his house, or he might cause the heart of his comrades to melt like his own'. 
tradições do Antigo Oriente Próximo, dentre os quais tenho sido incapaz de encontrar um único comparandum em fontes sumérias, babilônicas, hititas ou assírias. ${ }^{29}$ Por fim, devemos considerar as datas envolvidas aqui: as pesquisas mais recentes sobre a evolução dessa parte da Bíblia hebraica sugerem que ela não alcançou a forma que temos até o início do século vi a.C., ${ }^{30}$ que é certamente um pouco tarde para ter sido uma influência formadora da tradição homérica.

Pode-se argumentar que a influência ainda é possível, se não dos próprios Juizes e Deuteronômio, ao menos das narrativas ou tradições das quais esses textos se desenvolveram. Mas então temos que considerar a proeminência do motivo na tradição hebraica, pois os dois casos são breves e minimizados por seus contextos narrativos: em Juízes, por exemplo, o teste mais proeminente e longo vem em seguida, enquanto em Deuteronômio a passagem não é enfatizada. Essa é uma consideração importante, porque esses estudiosos que tentam explicar a Diapeira por meio dessas passagens hebraicas sugerem que o poeta grego (Homero ou um ancestral) foi tão comovido por esse motivo a ponto de usá-lo, muito embora ele não se encaixasse adequadamente em seu próprio poema, deixando traços denunciadores da derivação e recomposição para que todos vissem. Ainda assim, se o tema no cenário hebraico é tão raro e subestimado, por que um grego - ainda mais um poeta - foi particularmente comovido por ele? Tenho minhas dúvidas, para dizer o mínimo.

Assim, mesmo antes de começar a examinar a força do paralelo ao comparar esses textos com a suposta cópia grega, devemos, em primeiro lugar, nos perguntar se esse tema era tão proeminente a ponto de ser um candidato para cópia. Quando evocamos o texto grego, notamos imediatamente as diferenças um tanto importantes entre eles: no hebraico, o teste é planejado para diminuir o tamanho do exército, no grego, não; no hebraico, o teste é planejado pela divindade, mas no grego é acrescido às instruções da divindade com mínima introdução; no hebraico o exército é reduzido, enquanto no grego o exército todo, por fim, retorna à sua posição. $\mathrm{O}$ contexto e o processo são um tanto diferentes.

No entanto, ainda nos resta uma semelhança geral, e um indubitável desafio interpretativo na Ilíada. Vamos nos voltar mais uma vez para o antecedente tradicional, típico, e ver se as práticas do poeta em outras passagens podem nos ajudar a iluminar o problema. O problema fundamental, como vimos anteriormente, é que esse tipo de teste - se não for motivado para

${ }^{29}$ Procura-se em vão, por exemplo, na obra de referência de Younger 1990.

${ }^{30}$ Cf. Römer 2007. 
reduzir o tamanho do exército ou para se livrar de elementos difíceis em seu interior - não parece muito razoável. ${ }^{31}$

Mas a sugestão para recuar é uma ação muito comum, e (a menos que seja introduzida por intervenção divina para esse fim) ela sempre falha. ${ }^{32}$ Esse é o primeiro elemento típico importante aqui, pois no momento que um personagem na Ilíada propõe tal coisa, o público está ciente de que a sugestão vai falhar. Considere Agamêmnon depois da exibição desastrosa no segundo dia de batalha (9.16-29), ou novamente no Livro 14 quando as coisas parecem ainda mais desanimadoras (14.64-81); do lado troiano, podemos olhar para as duas sugestões de Polidamas a Heitor (12.208-29, 18.249-82). Em cada ocasião, a sugestão é negada, às vezes depois de um tempo como no Livro 9, e em outras imediatamente como nos Livros 12, 14, ou 18, mas apenas depois de reações daqueles no entorno do interlocutor. Essas ocasiões deixam claro por que a sugestão não deve ser seguida, por que o exército grego não pode deixar Troia e por que os troianos devem permanecer no campo: Diomedes e Nestor focam na derrota inevitável dos troianos (9.32-49, 42-78), Odisseu na necessidade de não deixar os gregos ouvirem tal plano em sua situação corrente (14.82-102, esp. 90-102), e Heitor na aparente covardia de Polidamas (12.230-50) e nas grandes necessidades militares dos troianos (18.284-309).

A falha da sugestão é, portanto, uma grande parte da questão fundamental do episódio, e Agamêmnon de fato parece entender isso, já que ele diz explicitamente antes do teste: "e vocês assegurem-se, muitos em muitos

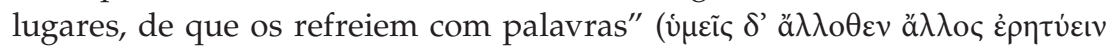
$\dot{\varepsilon} \pi \dot{\varepsilon} \varepsilon \sigma \sigma เ v, 2.75)$. Ele conjetura a intervenção dos basileis, e no contexto da fuga do exército, como uma reação a esse teste. Apesar de seu título antigo, a Diapeira não é fundamentalmente direcionada ao exército, cujo comportamento Agamêmnon prediz com acuidade, mas é direcionada aos basileis,

${ }^{31}$ Cf. West 1997, 207-8: "We expect him to inspirit them by telling them of his dream in which Zeus has apparently promised him victory, but he curiously fails to do so. Instead, Homer makes him deliver a thoroughly pessimistic speech, recommending that they abandon the war and go home. (...) The justification given for Agamemnon's paradoxical pessimism is that he wishes to 'test' the army, 'as is the proper custom'. Was there ever such a custom, in life or letters? It would not seem a very sensible one."

${ }^{32}$ Cf. 2.109-368: Agamêmnon sugere (109-41) - Odisseu refuta (183-332) - Nestor refuta (e amplifica) (333-68); 9.16-77: Agamêmnon sugere (16-29) - Diomedes refuta (31-49) - Nestor refuta (e amplifica) (52-77); 14.64-132: Agamêmnon sugere (64-81) - Odisseu refuta (82-102) [Agamêmnon se submete 103-8] - Diomedes refuta (e amplifica) (109-32); 12.208-50: Polidamas sugere (208-29) - Heitor refuta (230-50); 18.249-309: Polidamas sugere (18.249-82) - Heitor refuta (284-309). Para sequências um pouco menos complexas, cf. 2.224-42 (Tersites sugere Odisseu refuta), 5.241-50 (Estênelos sugere - Diomedes refuta). Para exemplos bem-sucedidos (todos introduzidos por intervenção diniva para esse fim), cf. 5.590-606 (Diomedes sugere - a multidão segue), 8.138-44 (Nestor sugere - Diomedes segue por fim), 15.281-300 (Toas sugere basileis seguem), 17.621-3 (Meríone sugere - Idomeneu segue); também Kelly 2007b, 164-5. 
que devem impedir seu recuo. Depois do desafio às estruturas de poder do exército grego na querela pública do Livro 1 , a necessidade de uma demonstração de apoio dos outros basileis é certamente mais importante, como Erwin Cook argumentou recentemente. ${ }^{33}$

O segundo contexto típico é o tema do "teste com palavras", em que o falante espertamente tenta provocar uma reação ao sugerir o oposto da verdade, e ao fazê-lo manipula a reação de acordo com seu próprio propósito. ${ }^{34}$ Considere a provocação de Zeus a Atena e Hera no início do Livro 4 da Ilíada, em que ele jocosamente sugere o fim da guerra, provocando uma resposta desmedida, antes de confirmar que Troia deve mesmo cair (4.5-6); ou Odisseu testanto Laerte no Livro 24 da Odisseia, em que ele provoca sentimentos de angústia paternal antes de confirmar ao velho homem que seu filho na verdade voltou para casa (Od. 24.239-40). O falante nesses casos obtém um benefício dessa interlocução, e a narrativa segue na direção estabelecida antes do "teste": Zeus força uma concessão de Hera para que ele possa saquear qualquer das cidades preferidas dela quando queira (4.30-49, 30-56), e a trégua é rompida; Odisseu revela-se a Laerte e o padrão de reconhecimento tem continuidade (Od. 24.287-92, 303-14, 320-46). Aqui no Livro 2 da Ilíada, Agamêmnon quer deixar o exército grego tinindo para um combate renovado, e isso é exatamente o que acontece.

Portanto, a Diapeira combina dois temas narrativos típicos: (a) a sugestão de recuo - que foca no modo no qual a sugestão falha - e (b) o motivo do "teste com palavras" - que funciona ao reverter ou enfraquecer as expectativas do interlocutor. Juntos esses motivos contam para a configuração do episódio, respondem às características problemáticas identificadas pelos pesquisadores e ajudam a explicar por que o poeta os escolheu.

Esse segundo caso mostra, de um ângulo um pouco diferente, os benefícios em usar nosso conhecimento da longa tradição oral de Homero. Se conseguirmos explicar a forma e a função de um episódio homérico

${ }^{33}$ Cook 2003.

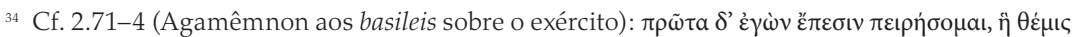

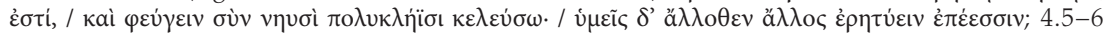

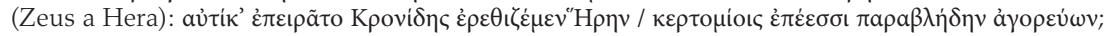

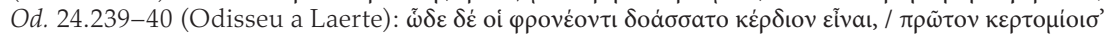

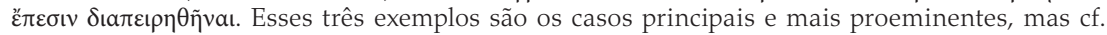

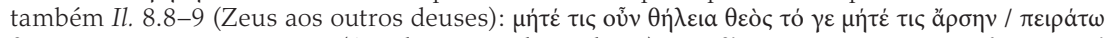

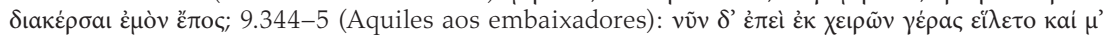

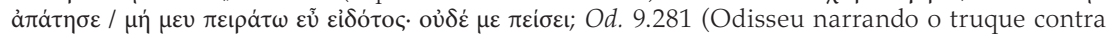

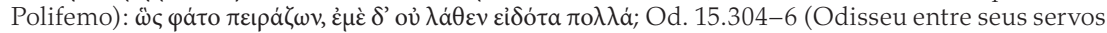

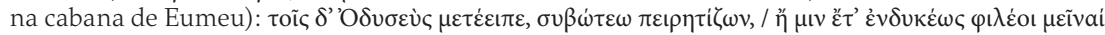

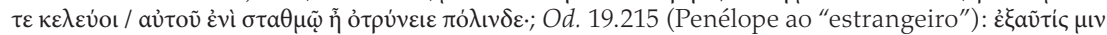

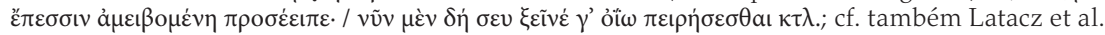
2003 , ad 2.73, 30 . 
usando o que já sabemos - que seu arcabouço poético era composto por um número grande mas finito de unidades repetidas, e que esse arcabouço foi desenvolvido e transmitido por um número grande, mas igualmente finito, de poetas - então talvez não precisemos da panaceia externa, especialmente em casos como esse, em que a suposta influência simplesmente não era tão influente.

\section{CONCLUSÃO}

Todos concordam que Homero tinha uma tradição, mas a concordância para aqui. Discordamos da natureza dessa tradição, de sua influência e mesmo de sua utilidade. Mas quase todos também concordam que a Ilíada e a Odisseia foram profundamente influenciadas por uma tradição oral de recomposição na performance. Devemos nos haver com essa influência. Ela tem sido lentamente, mas com crescente obstinação, esquecida em muito da pesquisa homérica moderna: enquanto Martin West quer "derrubar os oralistas das nossas costas", Donald Lateiner fala com desprezo da "pesquisa parryista, contadora de feijões", e Ken Dowden acha que a questão das fontes de Homero tem sido "obscurecida pelo discurso acadêmico em termos de uma poética oral", ${ }^{35}$ tenho tentado mostrar aqui que a tradição oral é importante, porque é útil: ela nos fornece as melhores ferramentas para lidar com nossos textos. Ao menos quando se trata de explicar a forma e a função dos poemas homéricos, devemos buscar outras ferramentas apenas quando aquelas nos deixarem na mão. ${ }^{36}$

${ }^{35}$ West 2003, 14; Lateiner 2004, 29; Dowden 1996, 47.

${ }^{36}$ Gostaria de agradecer a Christian e Erika Werner, Breno Sebastiani, André Malta e a todos no Departamento de Letras Clássicas e Vernáculas da Universidade de São Paulo pelo gentil convite de apresentar esse artigo no V Simpósio de Estudos Clássicos - Épica Antiga, em 5-6 de novembro de 2012, e por sua generosidade e hospitalidade durante minha estadia.

Email do autor: adrian.kelly@balliol.ox.ac.uk

Tradução: Camila Aline Zanon

Revisão: Christian Werner 


\section{REFERÊNCIAS}

Burgess, J. 1996. “The Non-Homeric Cypria." TAPA 126: 77-99.

Burgess, J. 1997. "Beyond Neoanalysis: Problems with the Vengeance theory." AJP 118: 1-19.

Burgess, J. 2001. The Tradition of the Trojan War in Homer and the Epic Cycle. Baltimore: Johns Hopkins University Press.

Burgess, J. 2009. The Death and Afterlife of Achilles. Baltimore: Johns Hopkins University Press.

Burkert, W. 1984. Die orientalisierende Epoche in der griechischen Religion und Literatur. Heidelberg.

Burkert, W. 1992. The Orientalizing Revolution: Near Eastern influence on Greek Culture in the early Archaic period. Cambridge, Mass.: Harvard University Press.

Cook, E. 2003. "Agamemnon's Test of the Army in Iliad Book 2 and the Function of Homeric Akhos." AJP 124: 165-98.

Currie, B. 2006. "Homer and the early Epic tradition." In Epic Interactions: papers in honour of Jasper Griffin, eds. M. Clarke, B. Currie, R. O. A. M. Lyne, 1-46. Oxford: Oxford University Press.

Currie, B. 2012. "The Iliad, Gilgamesh and Neoanalysis." In Homeric contexts: neoanalysis and the interpretation of oral poetry, ed. Franco Montanari, Antonios Rengakos, Christos C. Tsagalis, 543-80. Berlin-Boston: De Gruyter.

Danek, G. 1998. Epos und Zitat: Studien zu den Quellen der Odyssee. Vienna.

Dihle, A. 1970. Homer-Probleme. Opladen.

Dowden, K. 1996. "Homer's sense of text." JHS 116: 47-61.

Edwards, M. 1991. The Iliad A Commentary; Volume V: Books 17-20. Cambridge: Cambridge University Press.

Fenik, B. 1964. Iliad X and the Rhesus Myth. Brussels: Latomus.

Foley, J. M. 1991. Immanent Art: from Structure to Meaning in Traditional Oral Epic. Bloomington: Indiana University Press.

Frolov, S.; A. Wright. 2011. "Homeric and Ancient Near Eastern Intertextuality in 1 Samuel 17." Journal of Biblical Literature 130(3): 451-71.

Gordon, C. Homer and Bible: the Origin and Character of East Mediterranean Literature. Ventnor (NJ): Ventnor Publishers, 1967.

Hamblin, W. J. Warfare in the Ancient Near East to 1600 BC: Holy Warriors at the Dawn of History. London: Routledge, 2006.

Haubold, J. 2002. "Greek epic: a Near Eastern genre?" Proceedings of the Cambridge Philological Society 48: 1-19.

Haubold, J. 2006. "Homer between East and West." Classics@ 3.

Haubold, J. Greece and Mesopotamia: Dialogues in Literature. Cambridge (no prelo).

Hölscher, U. 1955. "Review of Schadewaldt (1951) (1965)." Gnomon 27: 385-99.

Kakridis, J. Th. 1949. Homeric Researches. Lund.

Kelly, A. 2007a. "How to End an Orally-Derived Epic Poem." Transactions of the American Philological Association 137: 371-402.

Kelly, A. 2007b. A Referential Commentary and Lexicon to Homer Iliad VIII. Oxford: Oxford University Press. 
Kelly, A. 2008. "The Babylonian Captivity of Homer: the case of the DIOS APATE." RM 151: 259-304.

Kelly, A. 2011. "The audience expects: Odysseus and Penelope." In Orality, Literacy, and Performance in the Ancient World (Orality and Literacy in the Ancient World, vol. 9), ed. E. Minchin, 3-24. Leiden: Brill.

Kelly, A. 2012. "The mourning of Thetis: 'allusion' and the future in the Iliad." In Homeric contexts: neoanalysis and the interpretation of oral poetry, ed. Franco Montanari, Antonios Rengakos, Christos C. Tsagalis, 211-56. Berlin-Boston: De Gruyter.

Kelly, A. 2013. "Homeric Battle Narrative and the Ancient Near East." In Defining Greek Narrative, ed. D. Cairns \& R. Scodel. Edinburgh (no prelo).

Knox, R.; J. Russo. 1989. "Agamemnon's Test: Iliad 2.73-75." CA 8: 351-8.

Kullmann, W. 1960. Die Quellen der Ilias. Wiesbaden.

Latacz, J. et al. 2003. Homers Ilias: Gesamtkommentar, Band II 2: Zweiter Gesang. Munich.

Lateiner, D. 2004. "The Iliad: an unpredictable classic." In The Cambridge Companion to Homer, ed. R. Fowler, 11-30. Cambridge: Cambridge University Press.

Lohmann, D. 1970. Die Komposition der Reden in der Ilias. Berlin.

Montanari, F.; A. Rengakos; C. Tsagalis, eds. 2012. Homeric Contexts: Neoanalysis and the Interpretation of Oral Poetry. Berlin: De Gruyter.

Most, G. W. 1997. "Hesiod's myth of the five (or three or four) races." PCPS 43: 104-27.

Niditch, S. 1993. War in the Hebrew Bible: a study in the ethics of violence. Oxford: Oxford University Press.

Pestalozzi. 1945. Die Achilleis als Quelle der Ilias. Zürich.

Römer, T. 2007. The so-called Deuteronomistic history: a sociological, historical and literary introduction. London-New York: T \& T Clark.

Schadewaldt, W. 1965. "Einblick in die Erfindung der Ilias: Ilias und Memnonis." In Von Homers Welt und Werk, 155-202. Stuttgart. 4th ed. (1st ed. 1951).

Schoeck, G. 1961. Ilias und Aithiopis: Kyklische Motive in homerischer Brechung. Zürich.

Scodel, R. 2004. "The Modesty of Homer." In Oral Performance and its Context, ed. C. Mackie, 1-19. Leiden: Brill.

Sehnert-Siebel, A. 1994. Volksverführung als schöne Kunst: die Diapeira in zweiten Gesang der Ilias als Lehrstück demagogischer Ästhetik. Frankfurt am Main.

Taplin, O. 1992. Homeric Soundings. Oxford: Clarendon Press.

Taylor. J. 2007. Classics and the Bible: Hospitality and Recognition. London: Duckworth.

De Vaux, R. 1972. The Bible and the Ancient Near East. London.

West, M. L. 1966. Hesiod Theogony. Oxford: Clarendon Press.

West, M. L. 1971. Early Greek Philosophy and the Orient. Oxford: Clarendon Press.

West, M. L. 1997. The East Face of Helicon: West Asiatic Elements in Greek Poetry and Myth, Oxford: Oxford University Press.

West, M. L. 2003. Iliad and Aethiopis. CQ 53: 1-14.

West, M. L. 2011. The Making of the Iliad: Disquisition and Analytical Commentary. Oxford: Oxford University Press.

Willcock, M. 1997. "Neoanalysis." In A New Companion to Homer, eds. I. Morris; B. Powell, 174-89. Leiden: Brill.

Younger, K. L. 1990. Ancient Conquest Accounts: A Study in Ancient Near Eastern and Biblical History Writing. Sheffield: Sheffield University Press. 
*

Abstract. What was handed down to Homer is the source of ever-increasing disagreement amongst modern scholars, not only as to the "what" of his inheritance but even the "how". Older dichotomies drew a sharp distinction between the repeated elements in Homeric poetry and the individual touches, labelling the former "tradition" and the latter "innovation". More recent scholarship, however, has shown the essential and constant interrelation of these two concepts: there is constant individuality in the formation and deployment of even the most common of features, whilst the most apparently innovative elements of Homeric poetry show the influence of standardisation and typicality we have come to expect. In other words, tradition is always innovative, and innovation is always traditional. Yet this subtle interplay seems to have been ignored in two important strands of modern Homeric scholarship, which we may term Neoanalysis and Orientalism: both of these schools of thought share assumptions about Homer's textual and traditional background which are unsupportable. This paper will address some famous examples of these two approaches, and suggests a more "traditional" countercase to both.

Keywords. Oralism, Homer, Neoanalysis, Orientalism, Ancient Near East, prospective lamentation. 